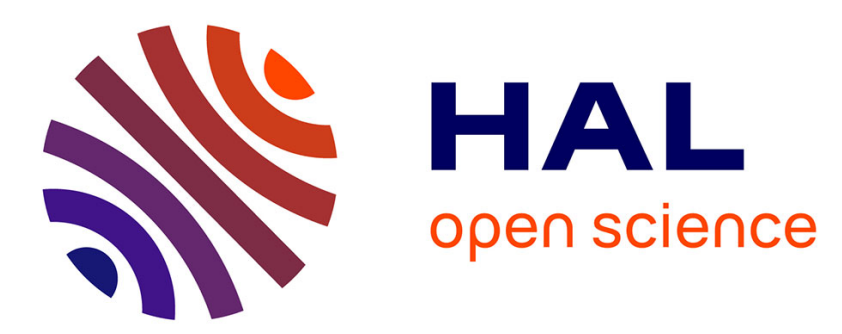

\title{
How does silicon lead the kinetics of the galvanizing reaction to lose its solid-solid character
}

\author{
J. Foct, G. Reumont, G. Dupont, P. Perrot
}

\section{To cite this version:}

J. Foct, G. Reumont, G. Dupont, P. Perrot. How does silicon lead the kinetics of the galvanizing reaction to lose its solid-solid character. Journal de Physique IV Proceedings, 1993, 03 (C7), pp.C7961-C7-966. 10.1051/jp4:19937148 . jpa-00251770

\section{HAL Id: jpa-00251770 https://hal.science/jpa-00251770}

Submitted on 1 Jan 1993

HAL is a multi-disciplinary open access archive for the deposit and dissemination of scientific research documents, whether they are published or not. The documents may come from teaching and research institutions in France or abroad, or from public or private research centers.
L'archive ouverte pluridisciplinaire HAL, est destinée au dépôt et à la diffusion de documents scientifiques de niveau recherche, publiés ou non, émanant des établissements d'enseignement et de recherche français ou étrangers, des laboratoires publics ou privés. 


\title{
How does silicon lead the kinetics of the galvanizing reaction to lose its solid-solid character
}

\author{
J. FOCT, G. REUMONT, G. DUPONT and P. PERROT
}

Laboratoire de Métallurgie Physique, URA 234 du CNRS, Université de Lille I, Bâtiment C6, 2ème étage, 59655 Villeneuve d'Ascq cedex, France

\begin{abstract}
The galvanizing reaction is very sensitive to alloying elements of steel. Therefore when industrial processes are considered the method is trying to counterbalance the influence of alloying elements in the steel by adding $\mathrm{Al}, \mathrm{Ni}, \mathrm{Mn}$ in the zinc bath. Although $\mathrm{Si}$ is often considered by steelmakers as necessary for killing and improving the mechanical properties of steel, it is usually undesirable by galvanizers because the reactivity of steel with zinc dramatically changes with $\% \mathrm{Si}$. This phenomenon is best illustrated by the thickness of the coating versus \% $\mathrm{Si}$ which presents a sharp maximum near $0.08 \% \mathrm{Si}$ and a minimum near $0.20 \% \mathrm{Si}$. This phenomenon discovered by Sandelin (1941) has not yet received any uncontroversial interpretation. In the present studies, we compared the morphologies and kinetics obtained in the same conditions for different silicon contents and we specially considered the coating obtained for small times of immersion. It is shown that in all cases, the first intermetallic phase which appears is $\zeta$. The experimental analysis of the compounds as well as thermodynamical calculations prove that the solubility of $\mathrm{Si}$ in $\zeta$ is negligible but of about 1 at.\% in $\delta_{1}$. Moreover, thermodynamical evaluation of Gibbs free energy of $\mathrm{Fe}-\mathrm{Zn}$ liquid shows that, if zinc diffusion in substrate is negligible, $\alpha-\mathrm{Fe}$ is in a metastable equilibrium at $450^{\circ} \mathrm{C}$ with the liquid containing about $7 \% \mathrm{Fe}$, which corresponds to the $\zeta$ compound. Our modelling shows that for Sandelin steels, the first stage of the reaction is not driven by diffusion of $\mathrm{Fe}$ in solid phases but in the liquid, leading to a linear variation of the reaction with time $t$. In a second stage the kinetics obeys a $\sqrt{t}$ law and corresponds to the solid state diffusion observed for hypoSandelin steel. The diffusion paths across liquid domains introduce supplementary degrees of freedom in the morphologies of the coating which then corresponds to numerous equilibria and pseudo-equilibria.
\end{abstract}

\section{Introduction}

Although industrial steel obviously differs from pure iron by being an alloy, it is frequently observed that during galvanizing at $450^{\circ} \mathrm{C}$ the coating that results from this reaction nearly obeys the Fe-Zn binary diagram. According to this diagram [1], from steel to zinc the following succession of phases is observed: $\Gamma, \delta_{1}, \zeta$ and $\eta \mathrm{Zn}$. In this case the kinetics of growth roughly vary as $\sqrt{\mathrm{t}}$ and thus corresponds to diffusion. This ideal situation is completely altered, however, when silicon is added to steel and the well known "Sandelin" behaviour is observed [2]. With the widespead killing of steel by 'silicon, the industrial consequences of the Sandelin phenomenon are considerable: the layer may be too thick or too thin, the appearance poor, corrosion resistance diminished and delamination etc... may occur.

However, it has been suggested that this behaviour is related to the supplementary degree of freedom corresponding to the introduction of an alloying element and that the determination of the diffusion paths could lead to a correct interpretation. Further knowledge of the $\mathrm{Fe}-\mathrm{Zn}-\mathrm{Si}$ ternary diagram was needed and that system has therefore been recalculated between $450^{\circ} \mathrm{C}$ and $900^{\circ} \mathrm{C}[5]$.

Another striking element to explain the Sandelin phenomenon was the identification by transmission 


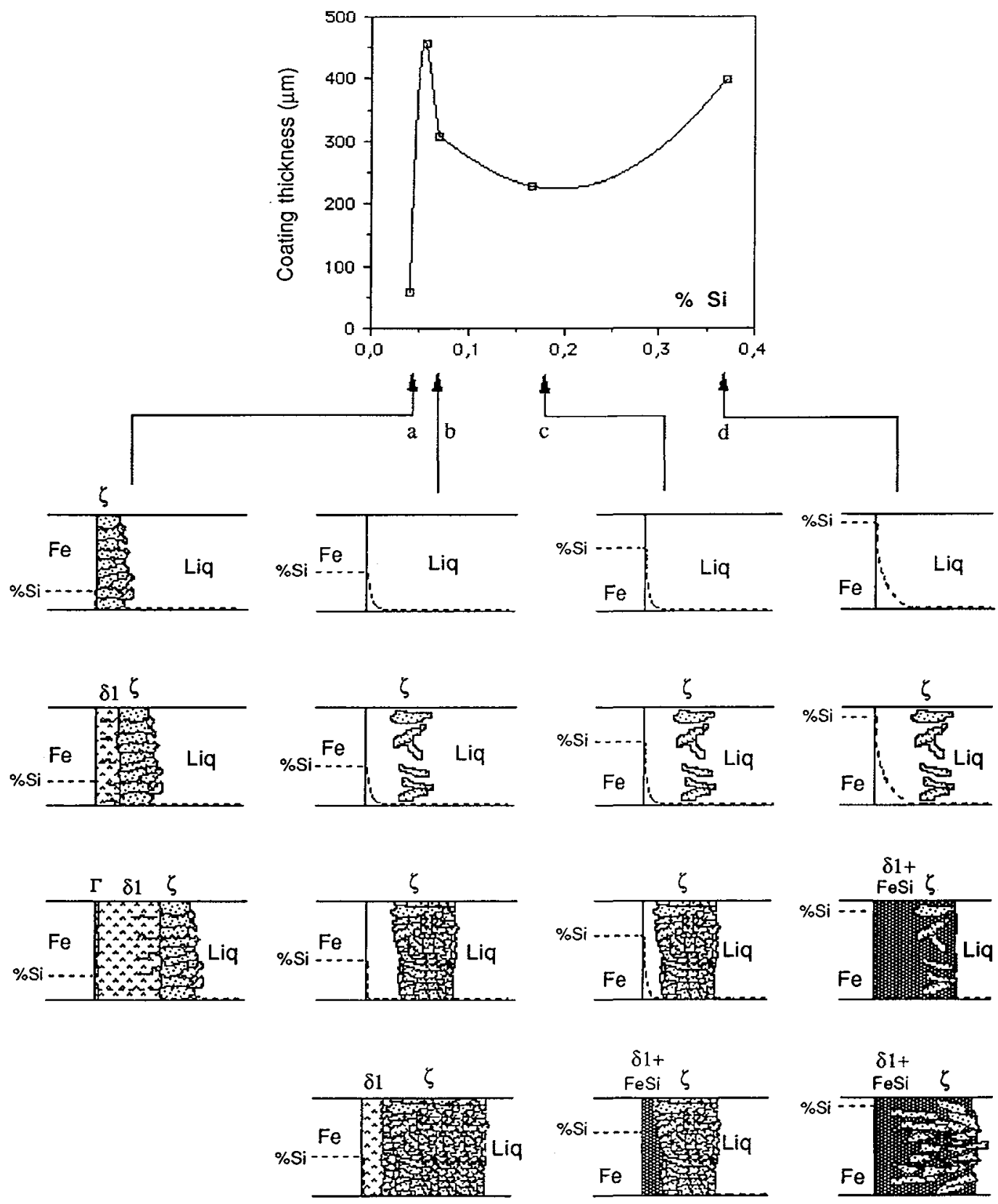

Fig. 1. Model of the influence of $\mathrm{Si}$ on the galvanizing reaction [9]

(a: hypo-Sandelin steel, b: Sandelin steel, $c$ and $d:$ hyper-Sandelin steel) 
electron microscopy of FeSi polyhedral particles in the galvanizing coating by Pelerin et al [6]. The interpretation given here is based on all these former results and on a careful analysis of the evolution of the microstructure as a function of the Si content.

\section{Experimental procedure}

Five industrial steels of which the silicon content varies from $0.01 \mathrm{wt} \%$ to $0.4 \mathrm{wt} \%$, have been studied. Steel A with less than $0.07 \mathrm{wt} \% \mathrm{Si}$, is a "hypo-Sandelin" steel. Steels B and C, containing about $0.07 \mathrm{wt} \% \mathrm{Si}$, are "Sandelin" steels [2]. Steels D and E are characterized as "hyper-Sandelin" steels.

Before being dipped in a zinc bath, industrial steels were prepared with a classical galvanizing treatment cycle. Samples were polished and then successively cleaned in an alkaline solution, pickled in an acid solution ( $\left.\mathrm{HCl}+\mathrm{H}_{2} \mathrm{O} 50 \%\right)$ to which a corrosion inhibitor (hexamethylene-tetramine) has been added, fluxed in an ammonium chloride and zinc chloride solution and dried at $120^{\circ} \mathrm{C}$. Samples were then dipped at $450^{\circ} \mathrm{C}$ in a zinc bath saturated with iron (about $0.04 \% \mathrm{Fe}$ ) for immersion time varying from 5 seconds to 10 minutes, and air-cooled. To reveal the galvanizing layers by micrography, samples were cut and polished to $1 \mu \mathrm{m}$. Interfaces between the different layers of the coating were shown by chemical pickling in a Nital $4 \%$ solution for a few seconds. Our main means of investigating the coating were optical and scanning electron microscopy coupled with energy-dispersive spectroscopy system.

\section{Morphologies and kinetics}

Thicknesses obtained after 9 minutes galvanizing at $450^{\circ} \mathrm{C}$ are shown in figure 1 . Clearly the "reactivity" of the steels, which can be measured by the thickness of the coating observed for the same duration of immersion and at the same temperature, is strongly related to the morphology, i.e. to the shape and extension of the Fe-Zn intermetallic compounds especially $\delta_{1}$ and $\zeta$ and to a lesser extent $\Gamma$.

For a low silicon content, which corresponds to the "hypo-Sandelin" steels, the morphology does not greatly differ from that obtained with iron. The growth and the morphology of the coating are described on figure 1a. The silicon concentration does not greatly impede the early formation of the $\zeta$-phase in contact with the steel surface which favours a heterogeneous nucleation. When the iron concentration in the $\zeta$ phase in contact with the steel increases, the conditions for the appearance of $\delta_{1}$ are fulfilled. Later, a faint layer of $\Gamma$-phase is likely to be observed between $\alpha$ and $\delta_{1}$, but the growth of $\Gamma$ is limited by the fact that the rate of formation at the iron side is "counterbalanced" by the rate of destruction on the $\delta_{1}$ side. All these mechanisms are driven by diffusion in the solid state and the resulting kinetics obeys a $\sqrt{\mathrm{t}}$ relation.

When the silicon concentration of steel is near $0.07 \mathrm{wt} \%$, the relative importance of the $\zeta$ compound dramatically increases and a thick two-phased $\zeta+\eta$ layer is overcoated by the $\eta$ zinc layer corresponding to the solidification of the liquid which was wetting the sample when pulled out the zinc pool. This concentration of $0.07 \mathrm{wt} \%$ corresponds to the Sandelin peak and the thickness of the coating, which in the present case is near $500 \mu \mathrm{m}$, is roughly 10 times that obtained with pure iron. Silicon builds up in the liquid neighbouring the interface.

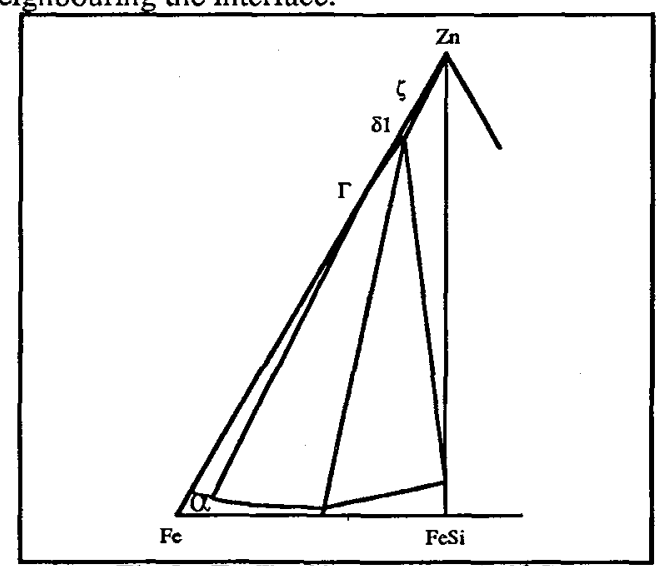

Fig. : Fe-Zn-Si system at $450^{\circ} \mathrm{C}$

From the phase diagram (figure 2), the liquid is no more in equilibrium with $\zeta$ but with $\delta_{1}$ [5]. However, the formation of $\zeta$-crystals is observed in the liquid, where the silicon content vanishes (figure 1b). In this intermediate liquid, the transport of iron is faster and and possibly governed by convection; the kinetics is faster and, as long as this intermediate liquid phase exists, may vary linearly with $t$. When the $\zeta$-layer formed by heterogeneous germination in the liquid (by comparison with $\zeta$ dross precipitation in pure zinc bath) is compact, $\delta_{1}$ in equilibrium with the liquid grows between the substrate and the $\zeta$-layer. Thus, the reaction slows down and the excess silicon dissolves in $\delta_{1}$.

For "hyper-Sandelin" steels, when the Si concentration is higher than $0.1 \mathrm{wt} \%$ (steels $\mathrm{D}$ and E), the morphology is characterized by a rather thick $\zeta$ layer and by a fine precipitation of FeSi inside the mixed $\delta_{1}+\zeta$ phases. In addition, the $\zeta$ domains present a polyhedral shape with well-developed planar interfaces; as already mentioned [6], the fine FeSi particles also display very clear planar interfaces. Usually, the $\zeta$ domains are well-developed and do not appear to interact with each other, being separated by 
a $\delta_{1}+\zeta$ "sea". The morphology described as hyper-Sandelin steels clearly differs from that obtained at the Sandelin concentration of $0.07 \mathrm{wt} \%$. The first stage of the process is very similar to (b), but when the liquid phase is confined between $\alpha$ and a continuous $\zeta$ layer, the conditions for the germination of FeSi are favoured by a higher Si supersaturation. The liquid can then solidify into a two-phased $\delta_{1}+\mathrm{FeSi}$ mixture (figure 1c). The period of linear variation of the kinetics with $t$ becomes shorter and the overall kinetics is slower. When the Si concentration continues to increase the nucleation and growth of $\zeta$ occur further towards the liquid, and the growth of $\zeta$ crystals perpendicular to the $\mathrm{Zn}$-steel interface is made easier, although the growth parallel to the interface and, therefore the welding of the $\zeta$ crystals, is delayed. The resulting thickness of the coating increases in comparison with (c) (figure 1d). The morphology observed is typical of this domain of composition and shows the easy growth of the $\zeta$-phase perpendicular to the Fe- $\mathrm{Zn}$ interface. The mixture $\delta_{1}+\mathrm{FeSi}$, "diffuse $\Delta$ ", on one side limits the growth of the $\zeta$-phase parallel to the interface and on the other is in contact with the liquid zinc, which leads to a larger concentration gradient and therefore to the coating becoming too thick.

As shown by figure 1 , this variation of the microstructure of the coating with the silicon content is also the source of changes in the kinetics of the galvanizing reaction. As a first approximation for hypoSandelin steels, the reaction obeys rather well a $\sqrt{t}$ relationship and, when Sandelin and hyper-Sandelin steels are considered, an initial t variation is observed. The results of short immersion times (figures 3 to 6 ) clearly show that kinetics of growth are related to a linear diffusion law with Sandelin and Hyper-Sandelin steels and to a $\sqrt{t}$ law with Hypo-Sandelin steels. Moreover, with the shorter galvanizing times, the total thickness of the coating is related to the $\zeta$-compound and the $\delta_{1}$-phase is very narrow.

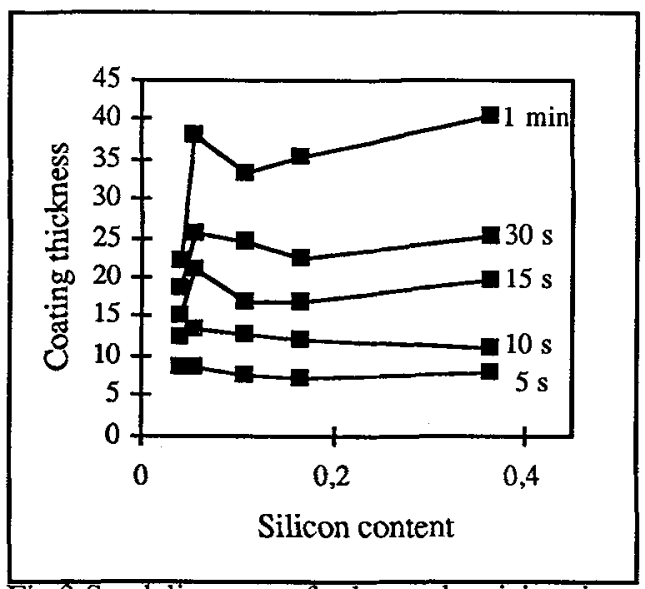

Fig.3:Sandelin curves for low galvanizing times at $450^{\circ} \mathrm{C}$

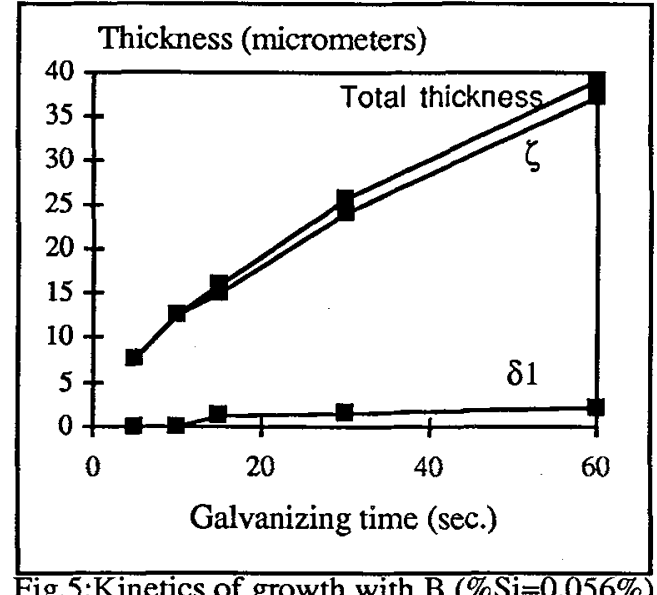

Fig.5:Kinetics of growth with $\mathrm{B}(\% \mathrm{Si}=0.056 \%)$

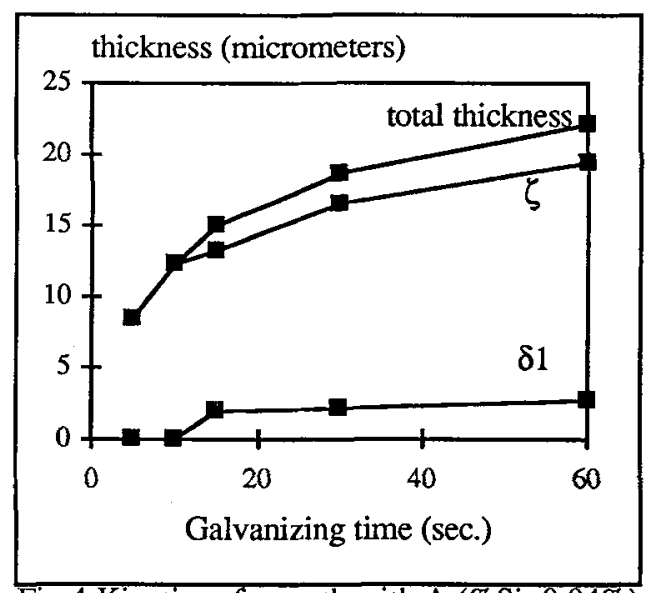

Fig.4:Kinetics of growth with $\mathrm{A}(\% \mathrm{Si}=0.04 \%)$

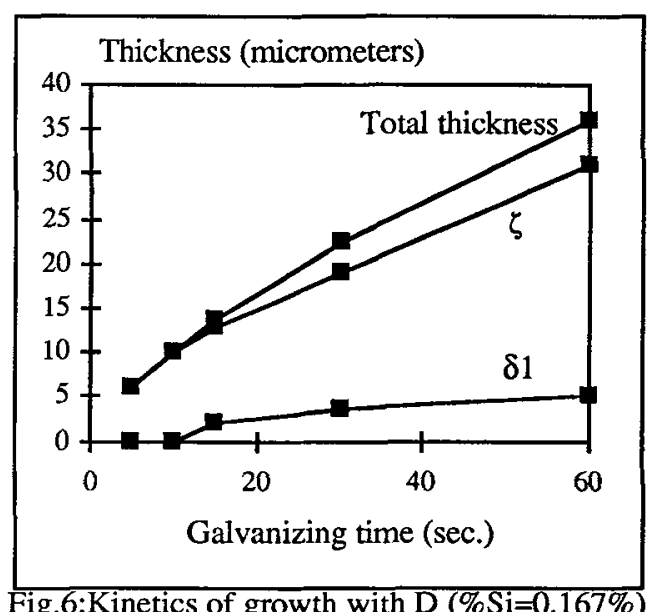

Fig.6:Kinetics of growth with $\mathrm{D}(\% \mathrm{Si}=0.167 \%)$ 


\section{Discussion}

Although it is frequently accepted that the first intermetallic compound that appears during the Fe- $\mathrm{Zn}$ reaction is $\zeta$, up to now, no clear interpretation has been proposed. In our opinion, the first obvious cause is that the zinc bath, misleadingly described as iron-saturated, is in fact " $\zeta$-saturated". Therefore, as soon as the iron concentration increases, an appreciable driving force for $\zeta$ precipitation has to be taken into account. Another factor that favours the germination and growth of the $\zeta$-phase is related to its crystallographic structure, which is much simpler than that of $\delta_{1}$, and to the atomic bonds which compared with those in $\delta_{1}$, are more metallic as shown by the hardnesses $\mathrm{Hv} \delta 1=340$ and $\mathrm{Hv} \zeta=112$ under $50 \mathrm{~g}[7,8]$.

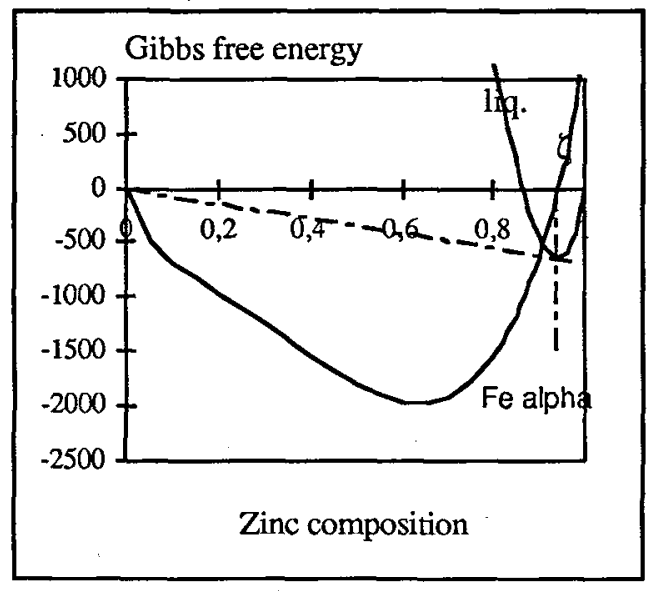

Fig.7:Gibbs free energy of liquid and iron phases

Previous thermodynamic calculations [1] proposed Redlich-Kister parameters of the Gibbs free energy of the liquid and $\alpha$-solid phases in the $\mathrm{Fe}-\mathrm{Zn}$ system (figure 7 ). If we suppose that the diffusion of zinc in iron is negligible, the substrate is in a metastable equilibrium at $450^{\circ} \mathrm{C}$ with the liquid containing about $7 \% \mathrm{Fe}$, which corresponds to the $\zeta$-compound. So, during the first immersion times, germination conditions are favourable to the $\zeta$-crystallisation near the substrate.

The question to be asked now concerns the role of silicon in the germination and growth of $\zeta$ phase. Electron microprobe analysis shows that the solubility of $\mathrm{Si}$ in $\zeta$-phase is vanishing. On the other hand, the $\delta_{1}$ phase is likely to dissolve about 1 at $\% \mathrm{Si}$ at $450^{\circ} \mathrm{C}$ and $\mathrm{FeSi}$ accepts about 1 at\% $\mathrm{Zn}$. Previous experimental data and thermodynamic calculations [5] lead us to propose the Fe-Zn-Si ternary diagram at $450^{\circ} \mathrm{C}$ shown in figure 2 . It is worth noticing that the $\zeta$-phase cannot lead to any binary equilibrium with $\mathrm{FeSi}$. The excess of silicon in the bath is likely to be reduced in two ways: (i) precipitation of FeSi particules; (ii) nucleation and growth of $\delta_{1}$ [9]. In these cases, the presence of a third metal introduces a supplementary degree of freedom in the morphologies of the coating which then corresponds to other kinetics of growth.

In order to study the influence of silicon on the nucleation of $\zeta$, vapor galvanizing experiments were performed according to the procedure we developped previously [10]. The conditions choosen did not allow the formation of liquid zinc in contact with the steel: the temperature of source $\left(494^{\circ} \mathrm{C}\right)$ and of the target $\left(500^{\circ} \mathrm{C}\right)$ were adjusted so that the chemical potential of zinc to be that of $\mathrm{FeZn}_{13}-\zeta$. Whatever the silicon content of the substrate is, the coating is identical and related to a diffusion path crossing successively domains of $\alpha, \Gamma, \delta_{1}$ and $\zeta$. The absence of the liquid phase near the substrate during the first times of immersion allows to a typical diffusion of iron and no great thickness of the coating due to silicon super-saturation.

Although the crystallographic structure of $\zeta$ appears to be simpler than that of $\delta_{1}$ and $\Gamma$, of which the nucleation is still more difficult, it is worth emphasizing that $\zeta$ is an intermetallic compound too, with a monoclinic structure [11] corresponding to a stacking of icosaedrons. Our Mössbauer study of this compound showed a well defined spectrum and therefore that iron occupies a well defined site. This indicates that the accomodation of Fe atoms coming from the bath by the $\zeta$ crystals is not easy. If $J_{L} \rightarrow \zeta$ is the number of Fe atoms accomodated by $\zeta$ by unit area of coating,

$$
J_{L-\zeta}=\varphi \exp \left(\frac{\Delta \mu_{\mathrm{L} \rightarrow \zeta}^{\mathrm{Fe}_{\mathrm{e}}}(\mathrm{T}, \mathrm{Si})}{\mathrm{RT}}\right)
$$

where $\varphi$ is a geometrical factor taking into account the morphology of the $\zeta$-phase, and $\Delta \mu_{L-\zeta \zeta}^{\mathrm{Fe}}$ the difference of chemical potential of $\mathrm{Fe}$ in the liquid and in $\zeta$. If the flux of $\mathrm{Fe}$ transported in the liquid phase is $\mathrm{J}_{\mathrm{L}}=\mathrm{D}(\mathrm{T})$ grad $\mathrm{Fe}_{\mathrm{L}}$, the linear dependance of the kinetics with time $\mathrm{t}$ when $\% \mathrm{Si} \geq 0.08 \%$ instead a $\sqrt{\mathrm{t}}$ variation, shows that $\mathrm{J}_{\mathrm{L} \rightarrow \zeta} \ll \mathrm{J}_{\mathrm{L}}$. When the liquid phase solidifies into $\delta_{1}+\mathrm{FeSi}$, the Fe diffusion takes place in the solid phase $\left(J_{\delta}\right)$ because the kinetics is still linear. It may be conclude that $J_{L} \rightarrow \zeta \ll J_{\delta}$. 


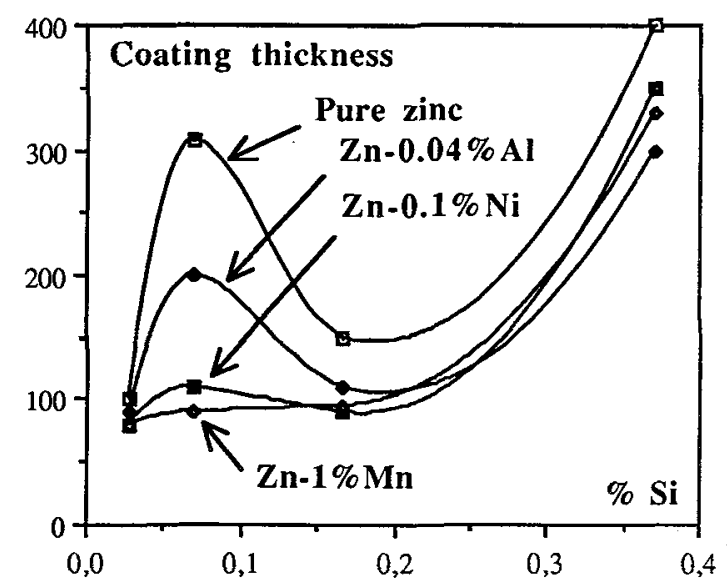

Fig. 8 : Influence of alloying bath on coating thickness

In order to overcome the detrimental effect of silicon in steels on the microstructure of the $\mathrm{Fe}-\mathrm{Zn}$ intermetallic compounds, several solutions had already been studied. For instance, nickel [12] or aluminium [13] additions to the zinc bath had been proposed and led to a decreasing thickness when galvanizing Sandelin steels. New processes based on $\mathrm{Mn}-\mathrm{Zn}$ alloying baths [14] are now studied (figure 8).

With that last element, we show that the thickness of the layer is rather less well developped than expected from conventional galvanizing bath when a little more than $0.5 \mathrm{wt} \% \mathrm{Mn}$ is added to the bath. This phenomenon becomes evident when Sandelin or hyper-Sandelin steels are galvanized for 9 minutes at $450^{\circ} \mathrm{C}$ in a $\mathrm{Zn}-1 \% \mathrm{Mn}$ bath:

the microstructure of such coatings are clearly related to hypo-Sandelin type.

Kinetics measurements also confirm that aspect. The disappearance of the Sandelin phenomenon when more than $0.5 \%$ of manganese are added to the zinc bath is based on thermodynamical considerations: Gibbs free energy of formation of different Fe-Si and Mn-Si compounds lead us to show that the $\mathrm{Mn}-\mathrm{Si}$ interaction is more attractive than the Fe-Si one [14]. In this case, a Mn-Si precipitation seems to be probable. In case of Sandelin steels, silicon coming from steel is attracted towards manganese in the bath and cannot lead to a Si-super-saturated layer near the substrate during the first times of immersion. Even with Sandelin or hyper-Sandelin steels, Fe-Zn compounds are able to grow on the substrate and a hypo-Sandelin morphology is observed.

\section{Conclusion}

The model that is proposed and summarized in figure 1 is based on the observation that a $\zeta \mathrm{Fe}-\mathrm{Zn}$ intermetallic compound is observed first and that the nucleation and growth of this phase occur at the steel interface when there is a low silicon content, or further into the liquid phase in the case of Sandelin and hyper-Sandelin steels. This work suggests many complementary experiments to determine the different kinetics related to the different stages, and the different means of accelerating or impeding the formation of the $\zeta$-phase inside the liquid. In this way better control of the morphology of the coating during industrial process may be achieved (alloying baths).

\section{References}

[1] DAUPHIN J.Y., PERROT P., TCHISSAMBOT U., Mém. Sci. Rev. Mét., 84, 6 (1987) 329

[2] SANDELIN R., Wire and wire products, 16, 1 (1941) 28

[3] HORSTMANN D., "Reactions between iron and molten zinc", Zinc Develop. Ass. (1978)

[4] GUTTMANN H., NIESSEN P., Proceedings CRM-ILZRO, Liège (1975) 198

[5] PERROT P., DAUPHIN J.Y., Calphad, 12, 1 (1988) 33

[6] PELERIN J., COUSTOURADIS D., FOCT J., Mém. Sci. Rev. Mét., 82, 4 (1985) 191

[7] FOCT J., BOUFFETTE-ARYANI J., IOST A., REUMONT G., PERROT P., GOODWIN F., WEGRIA J., Proceedings of Galvatech' 92, Amsterdam, Stahl und Eisen, (1992) 468

[8] FOCT J., Scripta Metallurgica et Materialia, 28, 1 (1993) 127

[9] FOCT J., PERROT P., REUMONT G., Scripta Metallurgica et Materialia, 28, 10 (1993)

[10] BRETEZ M., DAUPHIN J.Y., FOCT J., PERROT P., Z. Metallkde, 78 (1987) 137

[11] BROWN P.J., Acta Cryst., 15 (1962) 608

[12] SKENAZI A.F., ROLLEZ D., 15th. Int. Galvanizing Conf., Rome (1988) GE3

[13] GHUMAN A.R.P., GOLDSTEIN J.I., Metall. Trans., 2 (1971) 2903

[14] REUMONT G., DUPONT G., FOCT J., PERROT P., submitted Mém. Sci. Rev. Mét. (1993) 